\title{
CONTROL OF SEPARATION FLOW IN SUDDEN ENLARGEMENT
}

\author{
A. Abdel- Fattah \\ Mechanical Power Engineering Dept., Faculty of Engineering, \\ Minoufiya University, Shebin El-Kom, Egypt \\ ashourabdelfatah@yahoo.com
}

\begin{abstract}
In the present paper, an injection flow in separation zone in sudden enlargement has been studied experimentally and numerically. The injected flow is achieved through twelve slots placed around the inner side wall of the step. The static pressure is measured and calculated along the wall of sudden enlargement for different values of injection ratio $(Q)$ and injection flow angles. The average heat transfer variation with injection Reynolds number $\left(\operatorname{Re}_{\mathrm{J}}\right)$ has been obtained for different values of the injection flow angle. Velocity contours, turbulent kinetic energy contours and temperature contours are found. The flow Reynolds number of injected flow in this study is found to vary between 320 and 840 , the flow Reynolds number for the main flow is 5895 to 8450 at injection flow angles of $0^{\circ}, 15^{\circ}, 30^{\circ}, 45^{\circ}$ and $60^{\circ}$.
\end{abstract}

The results indicate that, the pressure recovery coefficient increases by decreasing the injection ratio and increasing the injection flow angle. The average heat transfer coefficient increases as both injection Reynolds number and injection flow angle increase. The numerical results show that two recirculation zones generate behind the step between the injected flow and the main flow. The size of these recirculation zones decreases by increasing the injection flow rate. The turbulent kinetic energy increases within the region between the recirculation zone and main zone. On the contrary, it decays by injecting flow in the recirculation zone. The zone for higher value of flow temperature decreases by injecting flow in the recirculation zone, and this zone increases as the injection flow rate increases. The comparison between the experimental and the numerical results using the k- $\varepsilon$ model with Leschziner and Rodi correction show a fairly good agreement.

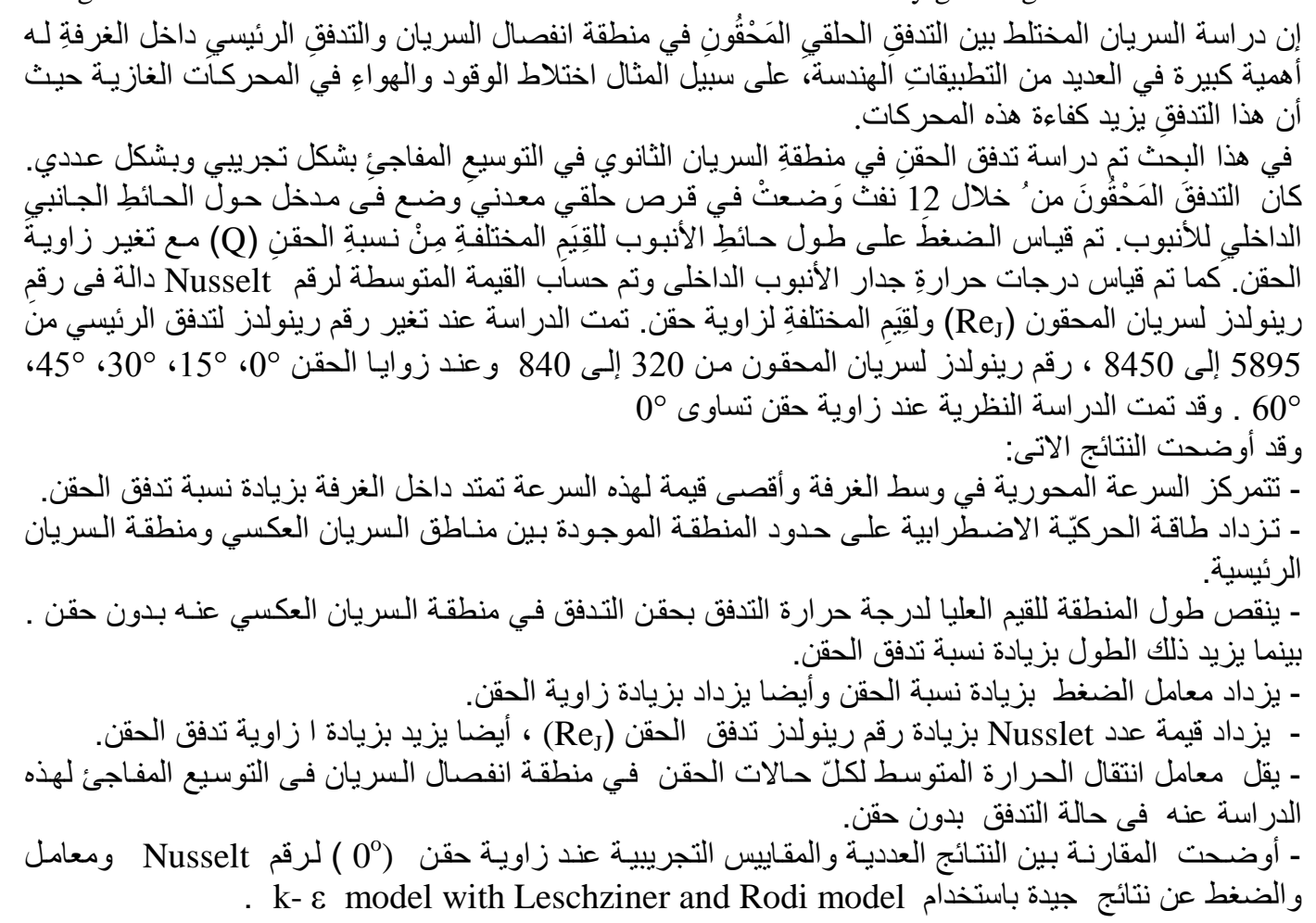

Keywords: Flow control, flow injection, flow separation, turbulence, heat transfer. 


\section{A. Abdel-Fattah, "Control of Separation Flow in Sudden Enlargement"}

\section{INTRODUCTION}

The mixing flow between injected annular flow and main flow inside a chamber are important for many engineering applications, for example fuel and air mixing in gas turbine engine combustor system. This flow is of interest to increase the efficiency and performance of combustor chamber. A number of investigations had studied facing step flow. Yilmaz and Öztop [1] were studied numerically the turbulent forced heat transfer for double forward facing step flow. They used the commercial program on FLUENT, to indicate the effect of step height, step length and Reynolds number on the heat transfer and fluid flow. Their results showed that, the second step can be used as a control device for both heat transfer and fluid flow. A steady - state heat transfer study for two dimensional laminar, incompressible, plane wall jet over a backward -facing step was carried out by Kanna and Das [2]. They studied the effect of Reynolds number, Prandtl number and step geometry on the heat transfer characteristics. Their results indicated that, when Reynolds number increases, the isotherms are deflected toward the recirculation region and are concentrated near the wall. Also, when Reynolds number increases, local Nussult number along the bottom wall increases to a peak value and is asymptotically reduced in the downstream direction. Seo and Parameswaran [3] studied numerically the steady and unsteady flow through a backward facing step. They used the standard k- $\varepsilon$ model with standard wall functions to produce buoyant flow for various Richardson number. Their results showed that, for the flow over the backward- facing step, buoyancy -driven vortex shedding has been noticed only in the turbulent flow when Richardson number increases to a critical value.

The control of the isothermal turbulent flow within a rearward- facing step combustor using countercurrent shear was studied experimentally by Forliti and Strykowoski [4]. Their results indicated that the use of suction based counter flow has essentially to separate mechanisms for achieving shear flow control. First counter flow has an effect of augmenting the natural reverse flow, caused by the sudden expansion of the step. The second mechanism employed using the counter flow is the modification of the shear layer near the expansion plane. Manca et al [5] studied numerically the effect of heated wall position on convection mixing in a channel with an open cavity. Their results are reported in terms of streamlines, isotherms, wall temperature, and the velocity profiles in the cavity for a Richardson number of 0.1 and values of Reynolds number of 100 and 1000. Their results showed that the maximum temperature value decreases as Reynolds number and Richardson number increase. The effect of the ratio between the channel and cavity heights is found to play a significant role on streamline and isotherm patterns for different heating configurations. The temperature distribution of an optic fiber traverse through a chemical vapor deposition reactor was simulated numerically by Iwanik and Chiu [6]. They indicated that, speed significantly affects fiber temperature inside the reactor, with a temperature changed over $50 \%$ observed under the studied conditions.

Dianat et al. [7] studied the highly turbulence flow inside gas-turbine combustors. In their study, they used the large eddy simulation (LES) of scalar mixing in a coaxial confined jet. Active control of turbulent separated flows over slanted surfaces is investigated by Brunn and Nitsche [8]. They used the simple half diffuser configuration to demonstrate the receptivity of actuator perturbations in a quasi- two dimensional separated shear layer in terms of frequency spectra of measured velocity fluctuations.

The experimental study of pressure and velocity fields arising during normal injection of a radial slot into ducted flow is described by Terekhov and Mshvidobadze [9]. Their results showed that negative static pressure, whose value increases with rise in the flow rate of the fan jet. Palm et al. [10] studied experimentally and numerically the inflow conditions for a gas turbine swirl combustor. Their results indicated that the axial velocity became increasingly asymmetric with increase of swirl intensity. The velocity increases from the inside to outside of the annular flow corresponding to an intensified radial movement towards the outer wall due to imposed swirl.

The effect of velocity ratio on the turbulent mixing of confined co-axial jets was reported by Ahmed and Sharma [11]. Mean velocity and turbulence intensity distributions at different stream wise locations were obtained using Laser Doppler Velocimeter (LDV) for different values of velocity ratios. Their results indicated that the mixing process in confined jets depends strongly not only on the velocity ratio, but also on the interaction between the boundary layer, mixing layer and the main flow, particularly when the area ratio is small. The experimental study of buoyancy opposed wall jet flow was studied by He et al [12]. They measured the local velocity, turbulence intensities and temperature using Laser Doppler Anemometry (LDA) and thermocouples, in the flow field produced by a buoyancy-opposed wall jet discharging into a slowly moving counter- current stream in a vertical section of plane geometry. Their results showed, as Richardson number increased, the influence of buoyancy opposing the flow is effective on the downward penetration of the jet and its lateral spread. The turbulent impinging twin-jet flow was studied 
experimentally and numerically by Abdel-Fattah [13]. His results showed that a sub atmospheric region occurs on the impingement plate. It increases strongly by increasing Reynolds number and decreases as the jet angle and/or the nozzle to plate spacing increase. The spreading of jet decreases by increasing nozzle to plate spacing. The intensity of re-circulation zone between two jets decreases by increasing nozzle to plate spacing and jet angle. The increase of turbulence kinetic energy occurs within flows with high velocity gradient.

The flow and thermal fields in a turbulent jet, impinging on a flat plate at an angle of incidence, has been studied numerically by Abdel- Fattah and Abd El-Baky [14]. The plate has a constant heat flux that transfers to the jet fluid and causes a temperature gradient in the fluid. Computations are carried out with $\mathrm{k}-\varepsilon$ and $\mathrm{v}^{\prime 2}$-f turbulence models. The flow characteristics were studied by changing plate inclination as $\left(0.0^{0} \leq \theta \leq 45^{\circ}\right)$, the distance between the nozzle exit and plate was within $2 \leq$ $\mathrm{H} / \mathrm{b} \leq 12$, and Reynolds number range was $2500 \leq$ $\mathrm{Re} \leq 12000$. Their results showed that the location of maximum heat transfer was affected by the angle of inclination. The location of this maximum shifts towards the up hill side of the plate by increasing the inclination angle. The value of maximum Nusselt number increases with increasing nozzle to plate spacing and pressure coefficient increases as the spacing decreases.

The present paper is concerned with an experimental and numerical study for steady and turbulent flow in a sudden enlargement with injection flow. Pressure recovery coefficient and heat transfer characteristics are investigated through changing the injection flow angle and injection Reynolds number. Also, velocity, turbulent kinetic energy and temperature contours for different injection flow rates and constant injection angle $\left(\theta=0^{\circ}\right)$ are predicted in this work.

\section{EXPERIMENTAL SETUP AND MEASURING METHODS}

The apparatus shown in Fig. 1 is designed to carry out the experimental work. The test rig consists of two centrifugal pumps (one for the main flow and other for the injected flow), pipeline connection, test section, injection system, and supply tank. The measuring devices constitute U-tube differential manometers and thermocouples. The test section is a circular sudden enlargement with area ratio of 9 to 1 , made of commercial steel pipe with inlet nominal diameter $25.4 \mathrm{~mm}\left(\mathrm{~d}_{\mathrm{n}}=1^{\prime \prime}\right)$, outlet nominal diameter $76.2 \mathrm{~mm}\left(\mathrm{D}_{\mathrm{n}}=3 "\right)$ and length $150 \mathrm{~cm}$. Twenty three pressure taps of diameter $(1 \mathrm{~mm})$ are distributed on middle surface of the test section to measure the pressure. These taps were connected to a multi utube monometer. The wall static pressure measured from these taps was repeatable within $\pm 1.5 \%$. Also, the test section is provided with twelve CopperConstantan thermocouples distributed along the inlet chamber surface to measure inner wall temperature. The injection system shown in figures (1b and 1c) contains the chamber which provides by twelve rectangular slots with different angles to inject hot water. Each rectangular slot has $15 \mathrm{~mm}$ depth and 2.0 $\mathrm{mm}$ width. The required operating flow rate is adjusted using the injected flow pump and control valves. The volume flow rate is measured by an orifice meter which is previously calibrated using collecting tank method. Uncertainly analysis indicated that maximum uncertainty in Nusselt number is $5 \%$.

The static pressure distribution, wall temperature distribution and outlet temperatures are measured. The pressure recovery coefficient is calculated using the equation:

$$
C_{P}=\frac{\bar{p}-\bar{p}_{i n}}{0.5 \rho U_{m}^{2}}
$$

where $\mathrm{Um}$ is the inlet mean velocity, $\bar{p}$ is the measured pressure and $\bar{p}_{\text {in }}$ is the measured pressure at inlet. The total net heat flow, q, can be expressed in terms of bulk- temperature difference by:

$$
\bar{q}=\dot{m} \mathrm{c}_{\mathrm{p}}\left(\bar{T}_{b_{\text {in }}}-\bar{T}_{b_{\text {out }}}\right)
$$

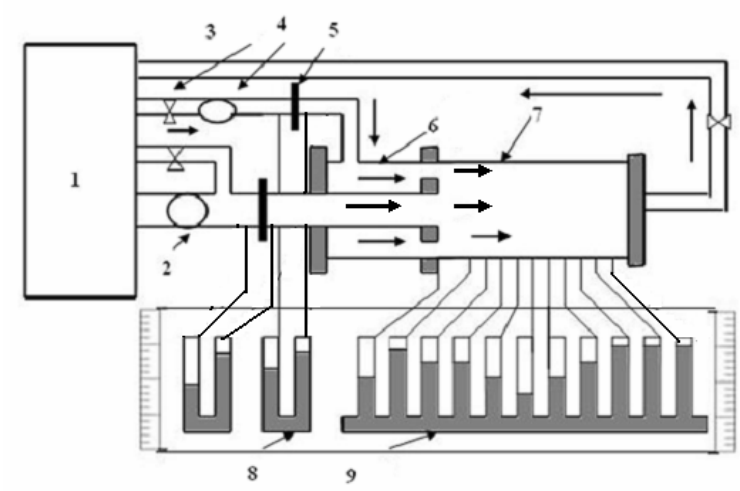
1. Supply tank
6. Injection system
2. Main pump
7. Test section
3. Control valve
8. U-tube differential manometer
4. Injection Pump
5. Orifice meter
9. Bank U-tube differential
manometer

Fig. 1.a Schematic layout of apparatus 

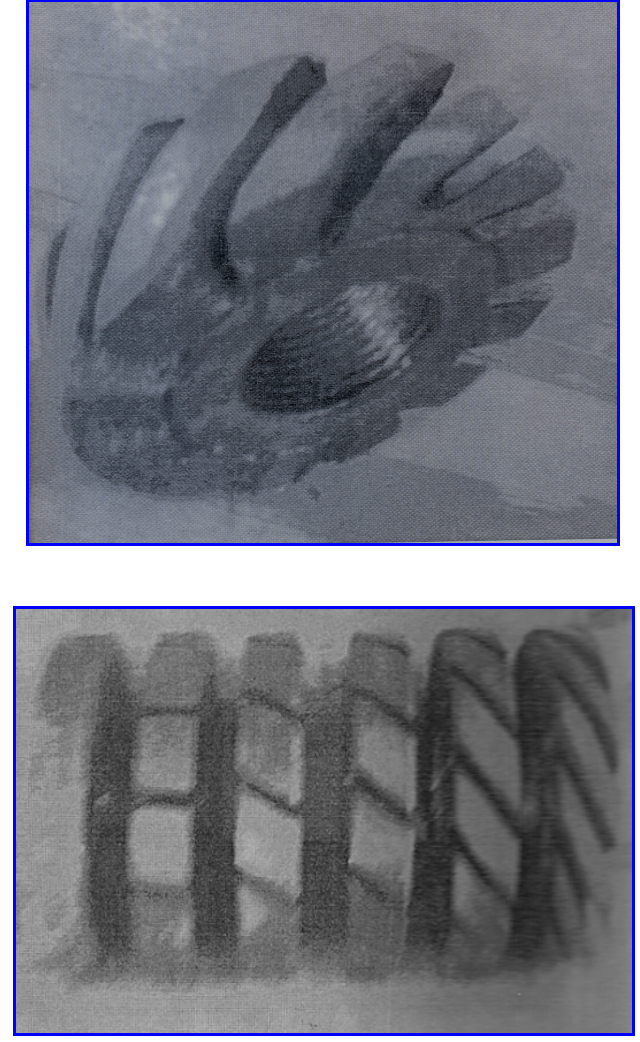

Fig. 1.b Flow guide for injection system

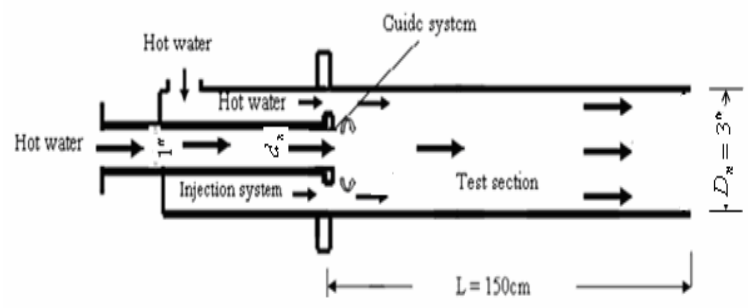

Fig. 1.c The injection system

where $\bar{T}_{b_{i n}}$ is the entrance mean bulk temperature and $\bar{T}_{b_{\text {out }}}$ is the exit mean bulk temperature, $\mathrm{cp}$ is the specific heat of fluid and $m$ mass flow rate, calculated as:

$$
m=\rho \mathrm{A}_{\mathrm{f}} \mathrm{U}_{\mathrm{m}}
$$

The net heat flow, $\bar{q}$, can be also expressed as:

$$
\bar{q}=h_{\mathrm{av}} A_{s}\left(\bar{T}_{b_{\mathrm{av}}}-\bar{T}_{W_{\mathrm{av}}}\right)
$$

Then, the average heat transfer coefficient $h_{a v}$ is evaluated from the equation:

$$
h_{a v}=\frac{\bar{q}}{A_{s}\left(\bar{T}_{b_{\mathrm{av}}}-\bar{T}_{W_{\mathrm{av}}}\right)}
$$

Where, $\bar{T}_{b_{\mathrm{av}}}$ is the fluid mean bulk temperature and $\bar{T}_{W_{\mathrm{av}}}$ is the wall mean temperature. The following equations are used in calculating these temperatures.

$$
\begin{aligned}
& \bar{T}_{b_{\mathrm{av}}}=\frac{\left(\bar{T}_{b_{\text {in }}}+\overline{\mathrm{T}}_{\mathrm{b}_{\text {out }}}\right)}{2} \\
& \bar{T}_{w_{\mathrm{av}}}=\sum_{i=1}^{i=N} \bar{T}_{i} / N
\end{aligned}
$$

where $\bar{T}_{i}$ is the measured temperature and $\mathrm{N}$ is the number of measured values. Then, Nusselt number, $\mathrm{Nu}$, is calculated, based on the hydraulic diameter, as follows:

$$
N u=\frac{h_{a v} d}{k_{c}}
$$

Where, $\mathrm{k}_{\mathrm{c}}$ is the thermal conductivity

\section{MATHEMATICAL MODELS}

For solving the problem at zero inlet flow angle, the flow is considered two dimensional, steady, turbulent and incompressible fluid flow with no heat dissipation. The physical model used in this study is shown in Fig. 1a.

Based on the characteristics scales of $\mathrm{d}_{m}$ and $U_{m}$, the dimensionless variables are defined as follows:

$$
\begin{aligned}
& r=\frac{\bar{r}}{d_{m}}, \quad z=\frac{\bar{z}}{d_{m}}, \quad k=\frac{\bar{k}}{U_{m}^{2}}, \\
& u=\frac{\bar{u}}{U_{m}}, \quad \mathrm{v}=\frac{\overline{\mathrm{v}}}{U_{m}}, \quad p=\frac{\bar{p}}{0.5 \rho U_{m}^{2}}, \\
& T=\frac{\left(\bar{T}-\bar{T}_{W}\right)}{\left(\bar{T}_{m}-\bar{T}_{W}\right)}, \quad \varepsilon=\frac{\bar{\varepsilon} d_{m}}{U_{m}^{3}}, \quad \mu_{t}=\frac{\bar{\mu}_{t}}{\mu}, \\
& \rho=\frac{\bar{\rho}}{\rho_{i}}, \quad N u=\frac{h_{a v} d}{k_{c}}
\end{aligned}
$$

Here the over bar represents the dimensional quantities. According to the above assumptions and dimensionless variables, the dimensionless governing equations are expressed as the follows:

Continuity equation

$\frac{1}{r}\left(\frac{\partial r \mathrm{u}}{\partial z}+\frac{\partial r \mathrm{v}}{\partial r}\right)=0$

Axial momentum equation

$$
\begin{gathered}
\mathrm{u} \frac{\partial \mathrm{u}}{\partial z}+\mathrm{v} \frac{\partial \mathrm{u}}{\partial r}=-\frac{\partial p}{\partial z}+\frac{\partial}{\partial z}\left[\left(\frac{1}{\operatorname{Re}}+\frac{1}{\mathrm{Re}_{t}}\right) \frac{\partial \mathrm{u}}{\partial z}\right]+\frac{1}{r} \frac{\partial}{\partial r} \\
{\left[r\left(\frac{1}{\mathrm{Re}_{1}}+\frac{1}{\mathrm{Re}_{t}}\right) \frac{\partial \mathrm{u}}{\partial r}\right]+\frac{\partial}{\partial z}\left(\frac{1}{\mathrm{Re}_{t}} \frac{\partial \mathrm{u}}{\partial z}\right)+\frac{1}{r} \frac{\partial}{\partial r}\left(\frac{r}{\mathrm{Re}_{t}} \frac{\partial \mathrm{v}}{\partial z}\right)}
\end{gathered}
$$


Radial momentum equation:

$$
\begin{aligned}
& \mathrm{v} \frac{\partial \mathrm{u}}{\partial z}+\mathrm{v} \frac{\partial \mathrm{v}}{\partial r}=-\frac{\partial p}{\partial r}+\frac{\partial}{\partial z}\left[\left(\frac{1}{\operatorname{Re}}+\frac{1}{\operatorname{Re}_{t}}\right) \frac{\partial \mathrm{v}}{\partial z}\right]+ \\
& \frac{1}{r} \frac{\partial}{\partial r}\left[r\left(\frac{1}{\operatorname{Re}}+\frac{1}{\operatorname{Re}_{t}}\right) \frac{\partial \mathrm{v}}{\partial r}\right]+\frac{\partial}{\partial z}\left(\frac{1}{\operatorname{Re}_{t}} \frac{\partial \mathrm{v}}{\partial z}\right)+ \\
& \frac{1}{r} \frac{\partial}{\partial r}\left(\frac{r}{\operatorname{Re}_{t}} \frac{\partial \mathrm{v}}{\partial r}\right)-\left(\frac{1}{\operatorname{Re}}+\frac{1}{\operatorname{Re}_{t}}\right) \frac{2 \mathrm{v}}{\mathrm{r}^{2}}
\end{aligned}
$$

Energy equation

$$
\begin{aligned}
& \mathrm{u} \frac{\partial T}{\partial z}+\mathrm{v} \frac{\partial T}{\partial r}=\frac{\partial}{\partial z}\left[\left(\frac{1}{\operatorname{Re} \operatorname{Pr}}+\frac{1}{\operatorname{Re}_{t} \operatorname{Pr}_{t}}\right) \frac{\partial T}{\partial z}\right] \\
& +\frac{1}{r} \frac{\partial}{\partial r}\left[r\left(\frac{1}{\operatorname{Re} \operatorname{Pr}}+\frac{1}{\operatorname{Re}_{t} \operatorname{Pr}_{t}}\right) \frac{\partial T}{\partial r}\right]
\end{aligned}
$$

The dimensionless equations for standard $\mathrm{k}-\varepsilon$ model are written as:

$$
\begin{aligned}
& \mathrm{u} \frac{\partial k}{\partial z}+\mathrm{v} \frac{\partial k}{\partial r}=\frac{\partial}{\partial z}\left[\left(\frac{1}{\operatorname{Re}}+\frac{1}{\sigma_{k} \operatorname{Re}_{t}}\right) \frac{\partial k}{\partial z}\right]+\frac{1}{r} \frac{\partial}{\partial r} \\
& {\left[r\left(\frac{1}{\operatorname{Re}}+\frac{1}{\sigma_{k} \operatorname{Re}_{t}}\right) \frac{\partial k}{\partial r}\right]+G-\varepsilon} \\
& \mathrm{u} \frac{\partial \varepsilon}{\partial z}+\mathrm{v} \frac{\partial \varepsilon}{\partial r}=\frac{\partial}{\partial z}\left[\left(\frac{1}{\operatorname{Re}}+\frac{1}{\sigma_{\varepsilon} \operatorname{Re}_{t}}\right) \frac{\partial \varepsilon}{\partial z}\right]+\frac{1}{r} \frac{\partial}{\partial r} \\
& {\left[r\left(\frac{1}{\operatorname{Re}}+\frac{1}{\sigma_{\varepsilon} \operatorname{Re}_{t}}\right) \frac{\partial \varepsilon}{\partial r}\right]+c_{1} \frac{\varepsilon}{k} G-c_{2} \frac{\varepsilon^{2}}{k}}
\end{aligned}
$$

Here $G$ is the rate of production of turbulent kinetic energy and is given by:

$$
G=\frac{2 S^{2}}{\operatorname{Re}_{t}}
$$

and

$$
S^{2}=\frac{1}{2}\left[\left(\frac{\partial \mathrm{u}}{\partial r}+\frac{\partial \mathrm{v}}{\partial z}\right)^{2}+2\left(\frac{\partial \mathrm{v}}{\partial r}\right)^{2}+2\left(\frac{\mathrm{v}}{r}\right)^{2}+2\left(\frac{\partial \mathrm{u}}{\partial z}\right)^{2}\right]
$$

The values of the model constants are taken as reported in [15] as follows:

$$
\begin{aligned}
& c_{1}=1.44, c_{2}=1.92, \quad c_{\mu}=0.09, \\
& \sigma_{\mathrm{k}}=1 \text { and } \sigma_{\varepsilon}=1.3
\end{aligned}
$$

Leschziner and Rodi [16] incorporated the effects of stream line curvature on $c_{\mu}$ in the form.

$$
c_{\mu}=\operatorname{Max}\left\{0.025, \frac{0.09}{\left[1+0.57 \frac{k^{2}}{\varepsilon^{2}}\left(\frac{\partial V_{t o t}}{\partial n}+\frac{V_{t o t}}{R_{c}}\right) \frac{V_{t o t}}{R_{c}}\right]}\right\}
$$

The curvature radius is calculated from:

$$
\frac{1}{R_{c}}=\frac{u \mathrm{v}\left(\frac{\partial \mathrm{v}}{\partial r}-\frac{\partial \mathrm{u}}{\partial z}\right)+\mathrm{u}^{2} \frac{\partial \mathrm{v}}{\partial z}-\mathrm{v}^{2} \frac{\partial \mathrm{u}}{\partial r}}{\left(u^{2}+\mathrm{v}^{2}\right)^{1.5}}
$$

The dimensionless form of dissipation equation for renormalization group model [17] is written as:

$$
\begin{aligned}
& u \frac{\partial \varepsilon}{\partial z}+\mathrm{v} \frac{\partial \varepsilon}{\partial r}=\frac{1}{r} \frac{\partial}{\partial r}\left[r\left(\frac{1}{\operatorname{Re}}+\frac{1}{\sigma_{\varepsilon} \operatorname{Re}_{t}}\right) \frac{\partial \varepsilon}{\partial r}\right]+\frac{\partial}{\partial z} \\
& {\left[\left(\frac{1}{\operatorname{Re}}+\frac{1}{\sigma_{\varepsilon} \operatorname{Re}_{t}}\right) \frac{\partial \varepsilon}{\partial z}\right]+\frac{\varepsilon}{k}\left(c_{1}-\frac{\eta\left(1-\frac{\eta}{\eta_{0}}\right)}{1+\beta \eta^{3}}\right) G-c_{2} \frac{\varepsilon^{2}}{k}} \\
& \text { where } \eta=\frac{k}{\varepsilon} \sqrt{2 S^{2}}
\end{aligned}
$$

The values of the model constants are taken as:

$$
\begin{gathered}
c_{\mu}=0.085, c_{1}=1.44, c_{2}=1.68, \sigma_{k}=0.719, \\
\sigma_{\varepsilon}=0.719, \eta_{0}=4.38 \text { and } \beta=0.012
\end{gathered}
$$

Here the dimensionless eddy viscosity $\mu_{t}$ is given by the relation

$$
\mu_{t}=c_{\mu} R_{e} \frac{\rho k^{2}}{\varepsilon}
$$

The computational domain boundaries are shown in Fig. 2. The boundary conditions for the above set of governing equations are as follows:

\section{a) Inlet boundary}

- At (a-b) and (e-f), the uniform velocity profiles and temperature are given by:

$$
\mathrm{v}=\mathrm{v}_{J} \sin \theta, \quad u=u_{J} \cos \theta \text { and } T=T_{j}
$$

- At (c-d), uniform velocity profiles and turbulent kinetic energy dissipation rate are given by $u=1$, $\mathrm{v}=0, T=1, \quad k=0.01 \quad$ and $\quad \varepsilon=\frac{c_{\mu} k^{1.5}}{0.1}$

\section{b) Wall boundary}

At (b-c, d-e, f-g and h-a), the no slip boundary condition on the wall is imposed, and using the wall function suggested by Launder and Spalding [15] $u=\mathrm{v}=0$ and $T=0$

\section{c) Exit boundary}

At (g-h), a zero gradient condition is employed for the outlet boundary. Although this boundary condition is strictly valid only when flow is fully developed, it is also permissible for sufficient downstream distance from the region of interest as reported in [18], i.e;

$$
\begin{aligned}
& \frac{\partial \phi}{\partial \bar{z}}=0 \text { and } \phi \quad \text { is either variable of } \\
& u, v, T, k \text { and } \varepsilon
\end{aligned}
$$



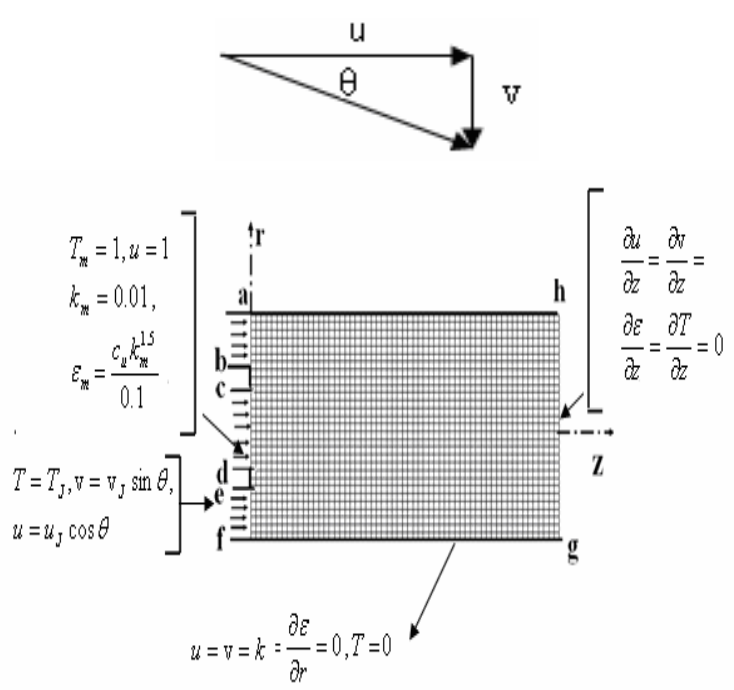

Fig. 2 Computational domain

\section{SOLUTION PROCEDURE}

The mathematical models described above consist of a set of differential equations subject to appropriate boundary conditions. To provide the algebraic form of the governing equations, a fully staggered grid system was adopted for the velocity components and the scalar variables. These equations were discretized using a control volume finite difference method (CVFDM). The numerical solution in the present work is accomplished using Semi- Implicit Method for Pressure Linked Equation (SIMPLE) utilized by Patankar [19]. The velocity components $u$ is calculated at the east and west faces of the main control volumes from the solution of the axial momentum equation. Similarly, the velocity component $\mathrm{v}$ at the north and south faces is calculated. Once the pressure correction equation is solved, the velocities and the pressure fields are then corrected. To complete iteration, the energy equation and the turbulent kinetic energy and energy dissipation rate equations are solved successively. The discretization equations were solved by the line by line procedure, which is a combination of GaussSeidel and tridiagonal matrix algorithm in the streamwise direction. The tridiagonal matrix algorithm (TDMA) was used to solve a set of discretization equation in the cross - equations in the cross- stream direction. Relaxation factors were employed to promote smooth convergence of the discretized equations. The employed relaxation factors were $0.5,0.5,0.5,0.8,0.85$ and 0.85 for $\mathrm{u}, \mathrm{v}$, $p^{\prime}, \mathrm{T}, \mathrm{k}$ and $\varepsilon$ respectively. The turbulent viscosity was under relaxed at a value of 0.85 . The converged criterion in this study was based on the successive changes in variables. All field variables were monitored, and the following condition was used to declare convergence:

$$
\operatorname{MAX}\left|\frac{\phi_{i, j}^{n}-\phi_{i, j}^{n-1}}{\phi_{i, j}^{n}}\right| \leq 10^{-4}
$$

In addition, the ratio of the difference between the inlet and outlet mass flow rates to the inlet mass flow rate relative mass imbalance was also examined. Convergence was declared if the relative mass imbalance was less than $10^{-3}$ and Eq. (20) was satisfied simultaneously. After the convergence at this time step, the entire variables take the initial condition values for the new time step. To verify the algorithm, numerical tests were performed to ensure that the solution was grid algorithm.

The grid points are distributed uniformly over the computational domain. A $155 \times 41$ grid points were fixed in the computational domain as shown in Fig. 2. Results of a grid independent study are shown in Fig. 3a. The effect of employing different the turbulence models on the variation of pressure coefficient is shown in Fig. 3b.

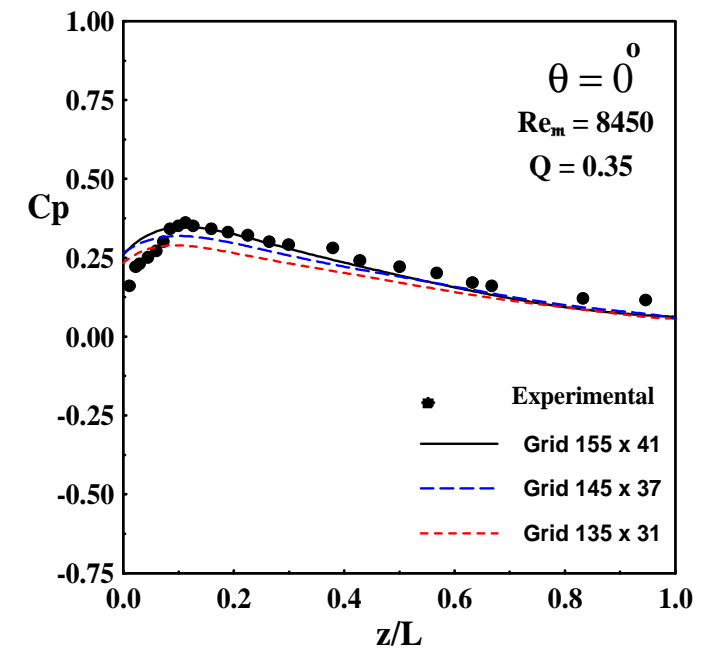

Fig. 3.a Effect of grid refinement on the pressure recovery coefficient

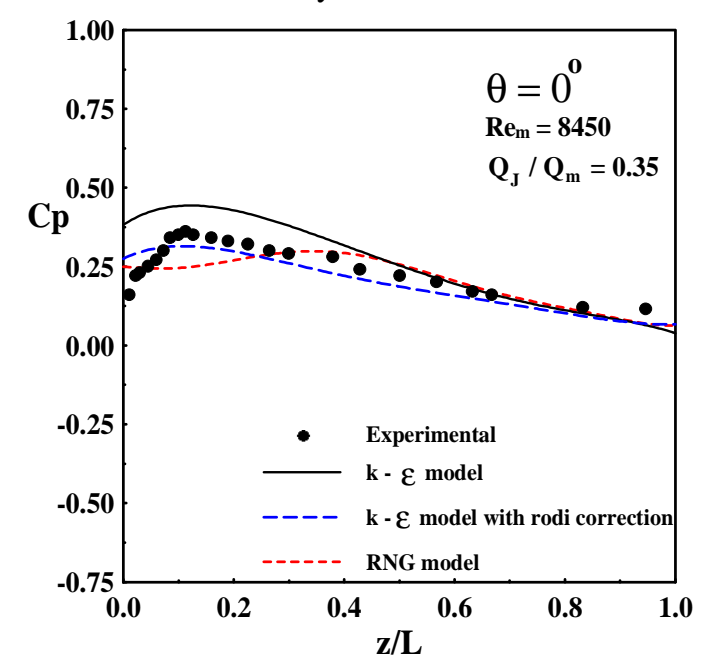

Fig. 3.b Effect of turbulence model on the pressure recovery coefficient 


\section{A. Abdel- Fattah, "Control of Separation Flow in Sudden Enlargement"}

\section{RESULTS AND DISCUSSION}

\subsection{Velocity Contours}

A representative selection of axial velocity contours $\left(\bar{u} / U_{m}\right)$ obtained numerically for different values of flow injection ratio at injection angle $(\theta=$ $0^{\circ}$ ) are shown in figure 4 . In figure $4 \mathrm{a}$, results of the flow without injected stream are presented. It can be seen that the velocity concentrates around chamber axis and decreases in the radial direction. It also decays in the downstream direction. This is apparently because the main flow becomes more radically spread in the downstream direction, at distances far from the inlet section.

(a)

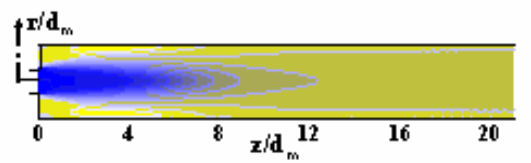

(b)

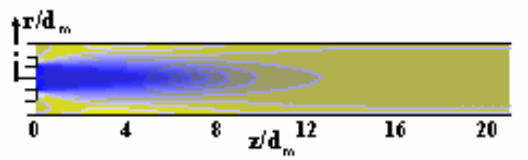

(c)

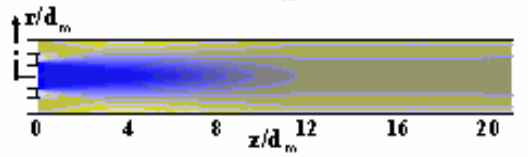

(d)

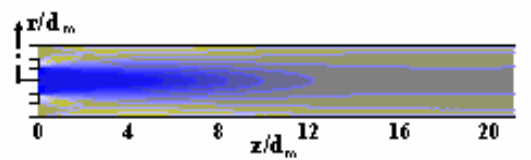

(e)

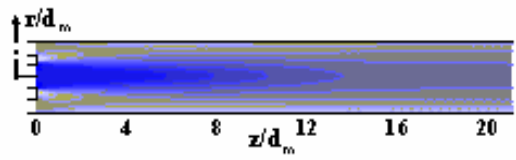

\begin{tabular}{|l|l|l|}
\hline No & $\mathrm{Q}$ & $\mathrm{Re}_{\mathrm{m}}$ \\
\hline $\mathrm{a}$ & 0 & 8450 \\
\hline $\mathrm{b}$ & 0.17 & 8450 \\
\hline $\mathrm{c}$ & 0.25 & 8450 \\
\hline $\mathrm{d}$ & 0.35 & 8450 \\
\hline $\mathrm{e}$ & 0.43 & 5895 \\
\hline
\end{tabular}

Fig. 4 Axial velocity contours $\left(\bar{u} / U_{m}\right)$ at injection

flow angle $\left(\theta=0^{\circ}\right)$ using the $\mathrm{k}-\varepsilon$ model with Leschziner and Rodi correction for different injection ratio, $\mathrm{Q}$, and $\mathrm{Re}_{\mathrm{m}}$

The main flow becomes more concentrated by injecting flow in recirculation zone. This flow concentration extends in the downstream direction by increasing the injection flow rate as shown in Figs. $4 \mathrm{a}-4 \mathrm{~d}$. At the same injection flow rate, as the main flow rate decreases, the flow becomes more concentrated at chamber center and the recirculation zone between the main flow and the injection flow becomes more clearly as shown in Fig. 4e.
The profiles of the radial velocity contours $\left(\bar{v} / U_{m}\right)$ are shown in Fig.5. From this figure, it can be seen that the intensity of secondary flow in recirculation region decreases by increasing the injection flow rate. This is due to the injection axial flow in recirculation zone behind the step at inlet. The re-circulation zone increases at higher value of injection flow ratio for constant value of injection flow rate and small value of the main flow as shown in Fig. 5e.

(a)

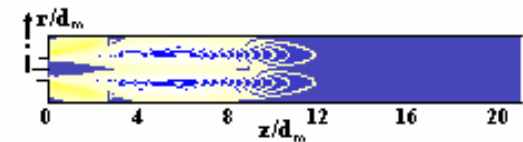

(b)
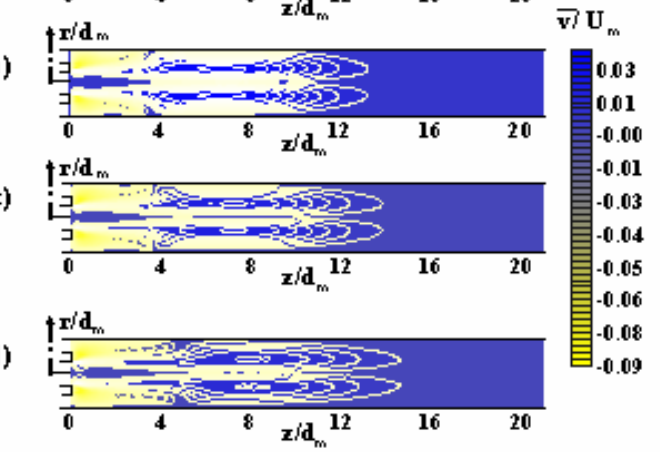

(e)

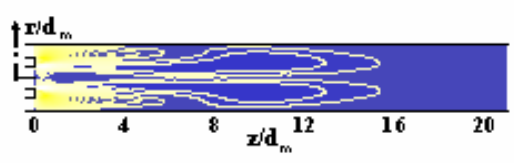

\begin{tabular}{|l|l|l|}
\hline No & $\mathrm{Q}$ & $\mathrm{Re}_{\mathrm{m}}$ \\
\hline $\mathrm{a}$ & 0 & 8450 \\
\hline $\mathrm{b}$ & 0.17 & 8450 \\
\hline $\mathrm{c}$ & 0.25 & 8450 \\
\hline $\mathrm{d}$ & 0.35 & 8450 \\
\hline $\mathrm{e}$ & 0.43 & 5895 \\
\hline
\end{tabular}

Fig.5. Radial velocity contours $\left(\overline{\mathrm{v}} / U_{m}\right)$ at

injection flow angle $\left(\theta=0^{\circ}\right)$ using the $\mathrm{k}-\varepsilon$ model with Leschziner and Rodi correction for different injection ratio, $\mathrm{Q}$, and $\mathrm{Re}_{\mathrm{m}}$

\subsection{Turbulent Kinetic Energy Contours}

The turbulent kinetic energy contours $\left(\bar{k} / \mathrm{U}_{\mathrm{m}}{ }^{2}\right)$ obtained numerically for $\mathrm{Re}=8055$ using the $\mathrm{k}-\varepsilon$ model with Leschziner and Rodi correction [16], are shown in Fig.6. From Fig. 6a, where the flow in sudden enlargement has no injection in recirculation zone, it can be noticed that increase in turbulent kinetic energy happens within regions between the recirculation zones and main zones. This is due to big velocity gradient in these regions. This turbulent kinetic energy decays by injecting flow in the recirculation zone. This is due to small velocity gradient in that regions see Figs $6 \mathrm{~b} \& 6 \mathrm{~d}$. 
(a)

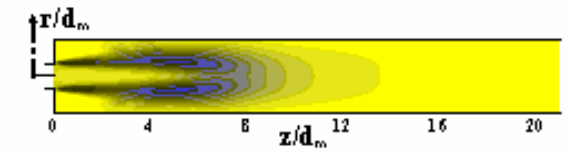

(b)

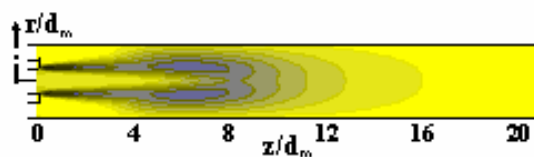

$\mathbf{r}^{\mathbf{r} / \mathbf{d}_{\mathrm{m}}}$

(c)

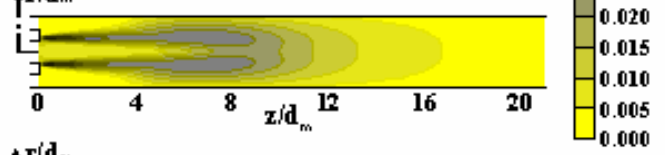

(d) $t^{r / d} \mathrm{~m}$

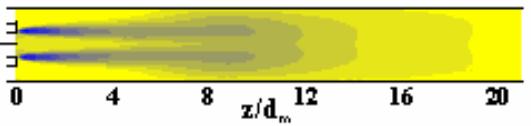

(e)

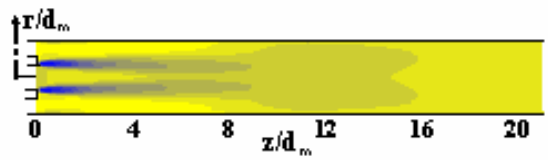

\begin{tabular}{|l|l|l|}
\hline No & $\mathrm{Q}$ & $\mathrm{Re}_{\mathrm{m}}$ \\
\hline $\mathrm{a}$ & 0 & 8450 \\
\hline $\mathrm{b}$ & 0.17 & 8450 \\
\hline $\mathrm{c}$ & 0.25 & 8450 \\
\hline $\mathrm{d}$ & 0.35 & 8450 \\
\hline $\mathrm{e}$ & 0.43 & 5895 \\
\hline
\end{tabular}

Fig. 6. Turbulent kinetic energy contours $\left(\bar{k} / U_{m}^{2}\right)$ at injection flow angle $\left(\theta=0^{\circ}\right)$ using the $\mathrm{k}-\varepsilon$ model with Leschziner and Rodi correction for different injection ratio, $\mathrm{Q}$, and $\mathrm{Re}_{\mathrm{m}}$

As the injection ratio increases at constant injection angle $\left(\theta=0^{\circ}\right)$ and constant main flow rate, the turbulent kinetic energy decreases but the length of higher turbulent kinetic energy increases. This is due to increase the size of mixing zone which occurs between the main flow and injection zone. The increment of turbulent kinetic energy in these regions decreases by increasing the injection flow rate. This is due to decrease of the velocity gradient between the injection flow and main flow, then the turbulence of flow reduces. The turbulence of the flow becomes more less for case of constant injection flow rate and decrease in main flow rate as shown in Fig. 6e

\subsection{Temperature Contours}

A representative selection of the temperature contours $\left(\frac{\left(\bar{T}-\bar{T}_{W}\right)}{\left(\bar{T}_{m}-\bar{T}_{W}\right)}\right)$ for $\mathrm{Re}_{\mathrm{m}}=8055$, using the $\mathrm{k}-\varepsilon$ model with Leschziner and Rodi correction [16] is shown in Fig.7. From Fig. 7a, where the flow in sudden enlargement was no injection in recirculation zone, it is seen that flow temperature is height at the initial zone of the pipe and it decreases in down stream direction. Also, it can be seen that the flow temperature in the recirculation zone is smaller than the flow temperature of pipe center. This is due to increase of the secondary flow which leads to increase of the heat transfer and, then heat rejection increases, consequently the temperature decreases in downstream direction, see Fig. 7a. By injecting hot fluid in recirculation zone at same temperature of main flow, the intensity of secondary flow decreases and the flow temperature in recirculation zones is higher than the flow temperature for the case without injection. This is due to decrease the flow turbulence in this zone then the heat rejection decreases and consequently the temperature increases in that region. As the injection flow ratio increases at constant injection flow angle $\left(\theta=0^{\circ}\right)$, the flow momentum increases then the length of the higher temperature region increases, see Fig. $7 b-7 d$. In case of constant injection flow rate and low main flow rate, the length of higher temperature region increases. This is due to decrease of the secondary flow and consequently the heat transfer decreases then the temperature becomes bigger as shown in Fig. 7e.

(a)

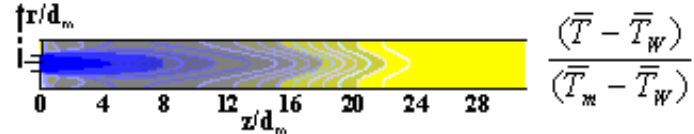

(b)<smiles>[Y17][AlH2]</smiles>

i

(c)

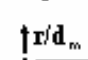

i

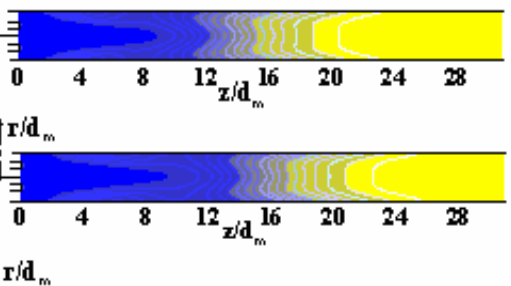

(e)

†r/d

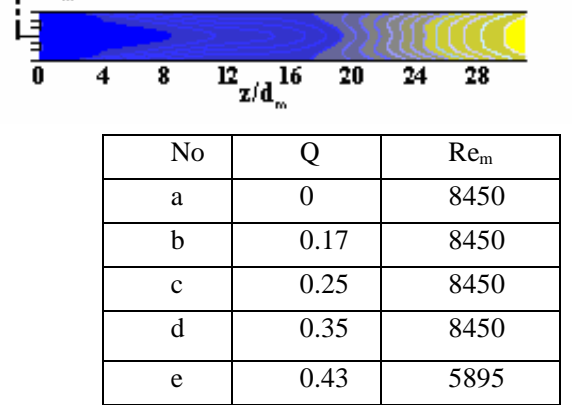

Fig. 7. Flow temperature contours $\left(\bar{T}-\bar{T}_{W}\right) /\left(\bar{T}_{m}-\bar{T}_{W}\right)$ at injection flow angle $\left(\theta=0^{\circ}\right)$ using the k- $\varepsilon$ model with Leschziner and Rodi correction for different injection ratio, $\mathrm{Q}$, and $\mathrm{Re}_{\mathrm{m}}$ 


\section{A. Abdel-Fattah, "Control of Separation Flow in Sudden Enlargement"}

\subsection{Effect of Reynolds Number on the Pressure} Recovery Coefficient

Figs 8a- 8e show the pressure recovery coefficient $\left(\bar{P}-\bar{P}_{i n} / 0.5 \rho U_{m}^{2}\right)$ measured for different values of inlet flow angle as a function of axial distance $(\mathrm{z} / \mathrm{L})$ at different values of the injection ratio. From these figures, in the case of sudden enlargement without injection flow $(Q=0)$, it is seen that, generally, the local pressure recovery decreases to reach a minimum value through the recirculation zone behind the step which causes increase of hydraulic losses. Then the pressure coefficient increases to maximum value at reattachment point which it starts to decrease again gradually in the downstream direction due to the friction effect. It is evident that in the case of no injection, a short region of favorable stream wise gradient exists after the step. In addition, it can be noticed that an increase of the injection ratio about zero value which causes an increase of the pressure coefficient.
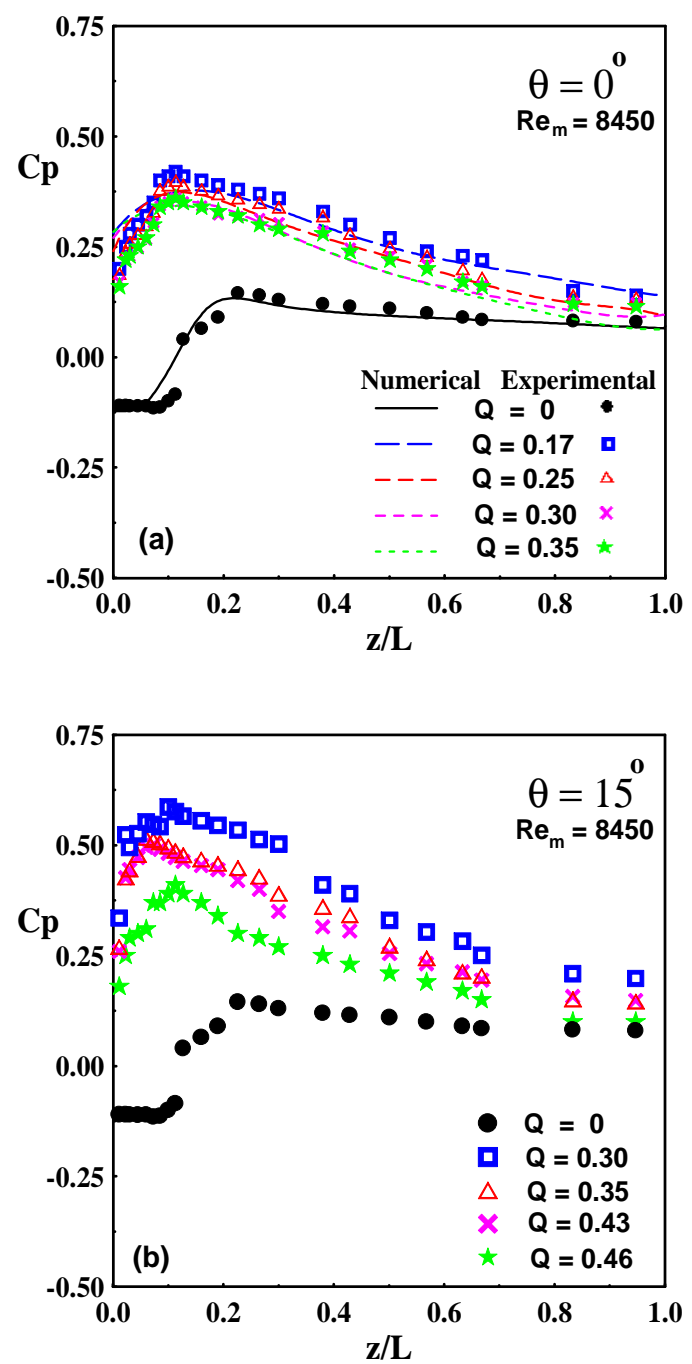
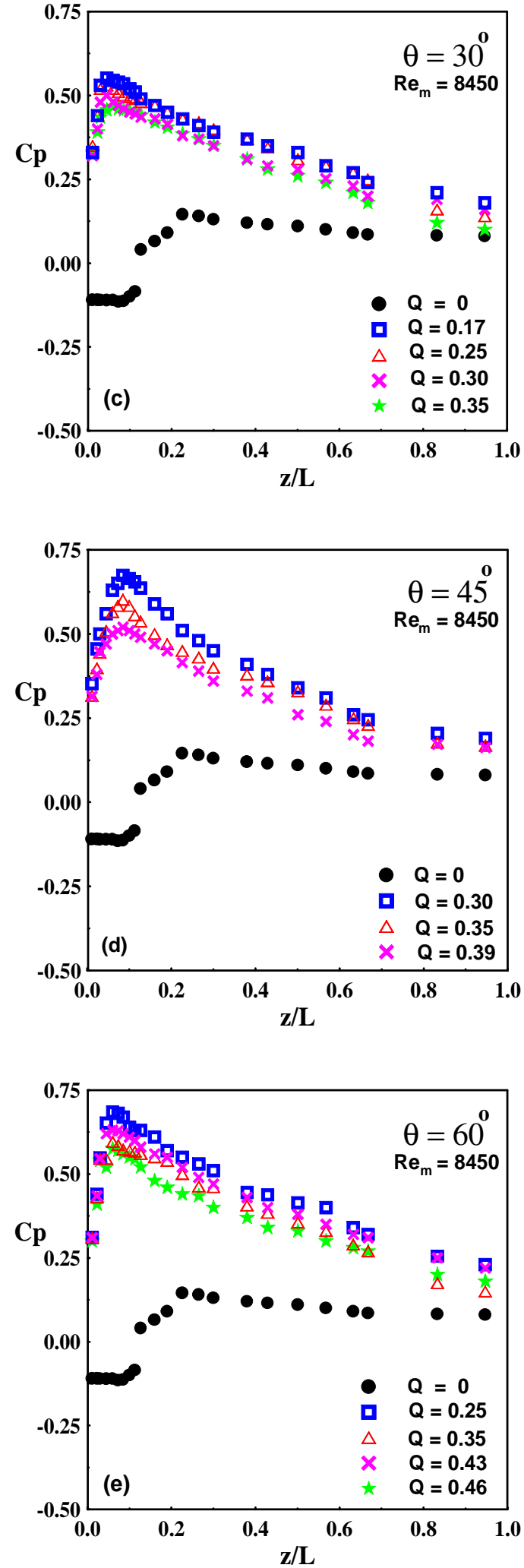

Fig. 8. Variation of the pressure recovery coefficient of different values of injection ratio, $\mathrm{Q}$, at injection flow angle $\left(0^{\circ}, 15^{\circ}, 30^{\circ}, 45^{\circ}\right.$ and $\left.60^{\circ}\right)$ at $\operatorname{Re}_{\mathrm{m}}=8450$ 
Also it can be seen that, the pressure recovery coefficient increases by increasing the injection flow angle. This can be explained due to increase of injection flow angle, which leads to increase the radial velocity and consequently the kinetic energy increases which effects on the pressure coefficient. Also, it is noticed that the peak of the pressure recovery decreases by increasing injection flow ratio $Q$. In addition, the figure $8 \mathrm{a}$ indicates the comparison between the experimental and numerical work using the $\mathrm{k}-\varepsilon$ model with correction of Leschziner and Rodi [16] at inlet flow angle $\left(\theta=0^{\circ}\right)$. The comparison gives a good agreement between the experimental and numerical results.

\subsection{Effect of the Injection Flow Angle on the Pressure Recovery Coefficient}

Figure 9 shows the measured pressure recovery coefficient $\left(\bar{P}-\bar{P}_{i n} / 0.5 \rho U_{m}^{2}\right)$ as a function of axial distance $(\mathrm{z} / \mathrm{L})$ at different values of the injection flow angle $\left(\theta=0^{\circ}, 30^{\circ}\right.$ and $\left.60^{\circ}\right)$ and constant value of injection ratio $(Q=0.35)$.

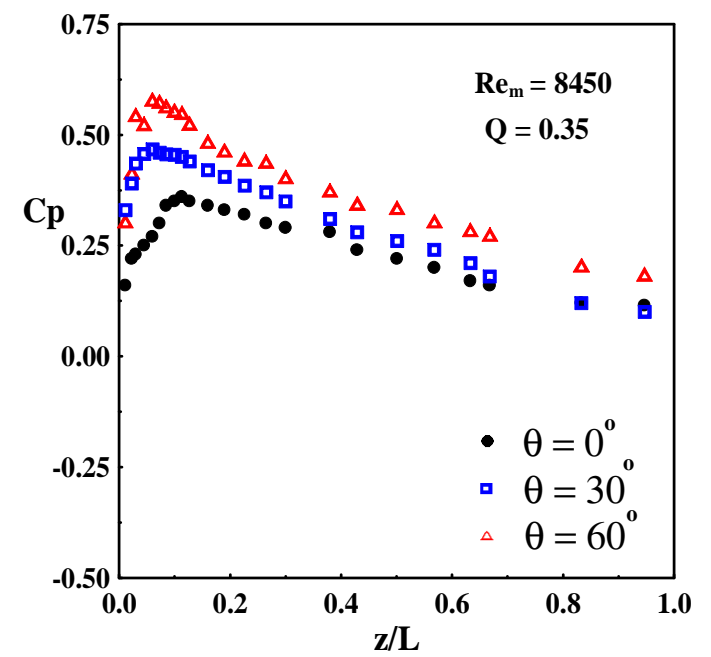

Fig. 9 Variation of pressure coefficient at different values of injection flow angle

From this figure, it can be seen that the pressure recovery coefficient before the reattachment point increases as the injection flow angle increases. This can be explained by increasing the injection flow angle, which leads to increase of radial component velocity, then the kinetic energy which converts into pressure increase. Also, the peak of the pressure coefficient moves award in the upstream direction with increasing injection flow angle. This is because the recirculation zones between the main flow and injection flow decreases with increasing the injection flow angle then the reattachment point shifts toward upstream direction.

\section{6 Average Heat Transfer}

Overall Nusselt number along the sudden enlargement are presented in this section to investigate the overall heat transfer characteristics as affected by main Reynolds number $\left(\operatorname{Re}_{\mathrm{m}}\right)$, injection Reynolds number $\left(\mathrm{Re}_{\mathrm{j}}\right)$ and injection flow angle.

Figure 10a represents Nusselt number as function of Reynolds number of main flow in sudden enlargement $\left(\operatorname{Re}_{\mathrm{m}}\right)$ without injection flow $(Q=0)$. From this figure, it can be seen that Nusselt number increases as Reynolds number of main flow increases. This is because the momentum of main flow increases by increasing Reynolds number, then the heat transfer increases. Also, It shows the comparison between the measured Nusselt number and numerically compared using the k- $\varepsilon$ model with correction of Leschziner and Rodi [16]. The comparison shows satisfactory agreement.

The effect of injection Reynolds number on Nusselt number at constant main Reynolds number $\left(\operatorname{Re}_{\mathrm{m}}=8050\right)$ is shown in Figs $10 \mathrm{~b}$ and 10c. The results indicted that, generally, the values of Nusselt number increase, due to the increase of injection Reynolds number at all values of injection flow angle. The reason for this tendency may be due to the momentum increases as Reynolds number of injected flow increases causing an increase in the heat transfer coefficient. Although Nusselt number increases as Reynolds number of injected flow increases but this increase does not reach to the value of Nusselt number in case of the flow without injection with constant value of main flow. This is due to reduce the recirculation zones. Injecting hot flow in recirculation zones causes decrease or finishes the intensity of secondary flow then the heat transfer decreases.

Figure 11 indicates the variation of Nusselt number against the injection flow angle, $\theta$, for different values of Reynolds number of $R_{J}$ and at $\mathrm{Re}_{\mathrm{m}}=8055$. It can be seen that, Nusselt number increases as the injection flow angle increases. This is because of the increase in momentum by increasing the injection flow angle which leads to increase of Nusselt number. Also, the heat transfer coefficient for all injection flow angle is less than a case of without the injection flow because the recirculation zone reduces. 

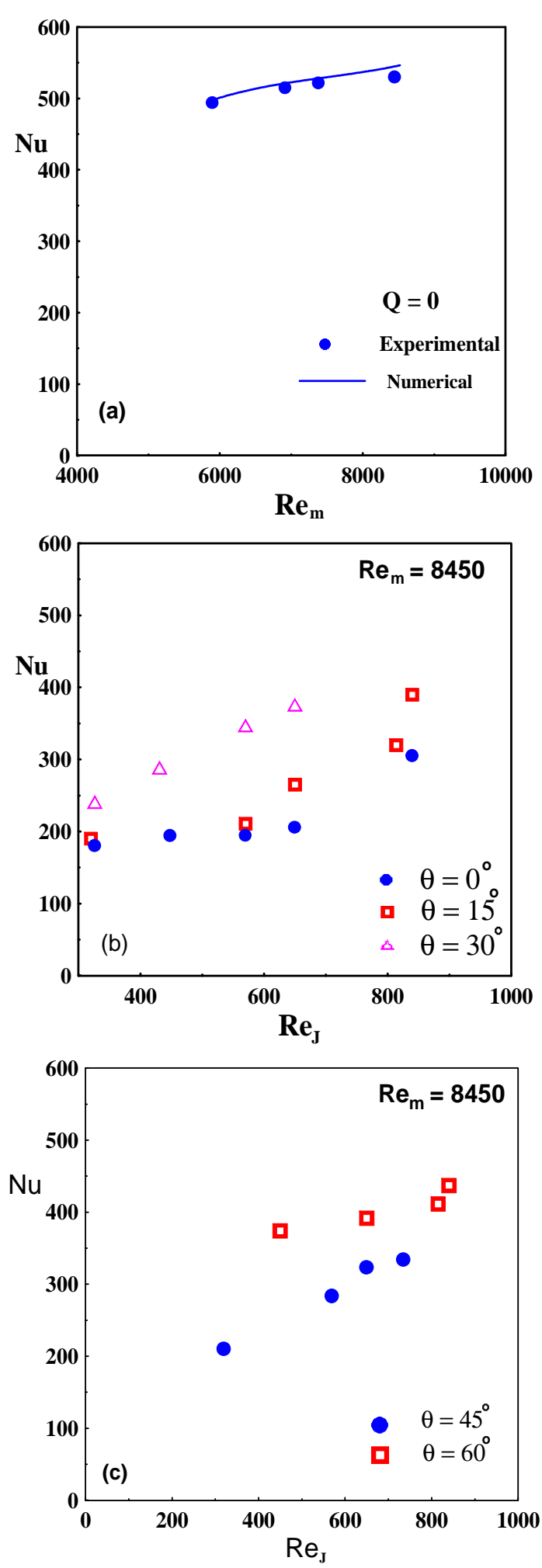

Fig.10 Variation of avarge Nusselt number with Reynolds number for injection flow angle (a) without injection $(\mathrm{Q}=0)$ using the $\mathrm{k}-\varepsilon$ model with Leschziner and Rodi correction, (b) $\theta=0^{\circ},=15^{\circ}$ and $30^{\circ}$ and, (c)

$$
\theta=45^{\circ} \text { and } 60^{\circ}
$$

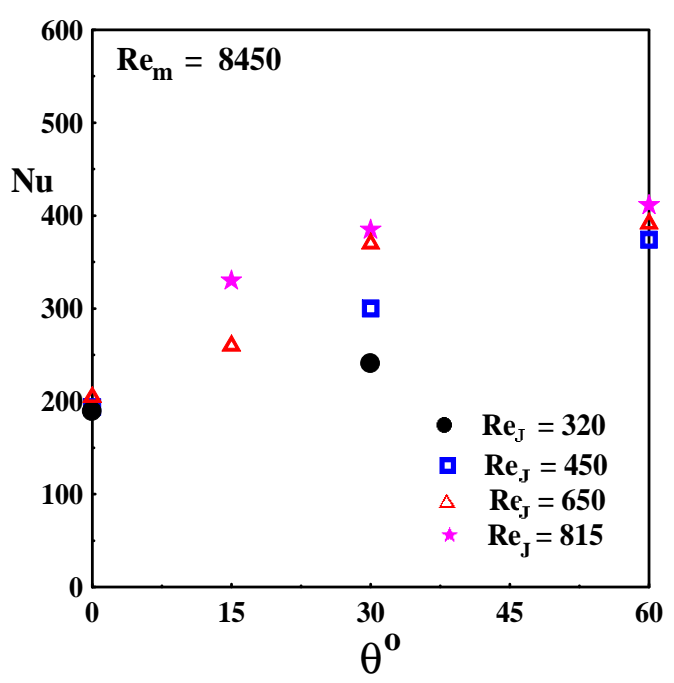

Fig.11 Variation of avarge Nusselt number with injection flow angle for different values of $\mathrm{Re}_{\mathrm{J}}$ at

$$
\mathrm{Re}_{\mathrm{m}}=8450
$$

\section{CONCLUSIONS}

The behavior of the fluid flow of steady incompressible turbulent with no heat dissipation in sudden enlargement with injection flow in separation zone was carried out experimentally and numerically.

The effect of injection ratio, Reynolds number and the injection flow angle on the pressure recovery coefficient and the heat transfer characteristics are studied experimentally. The velocity, turbulent kinetic energy and temperature contours are predicted numerically. The major conclusion of this research could be summarized as follows:

- The size of main recirculation zone which generates in sudden enlargement decreases by increasing the injection ratio although it still to be small than in the case without injection flow.

- Recirculation zones occur in the zones between the injection flow and main flow behind the step. The size of these recirculation zones increases by increasing the injection flow rate.

- The axial velocity concentrates in the chamber medial and the maximum value of this velocity extends in downstream direction by increasing the injection flow rate.

- The turbulent kinetic energy increases within region between the recirculation zones and main zone and it decays by injecting flow in the recirculation zone.

- The length of zone for higher value of flow temperature decreases by injecting flow in the recirculation zone, and that length increases as the injection flow rate increases.

- The pressure recovery coefficient increases by increasing injection ratio and also its peak value, at the reattachment point increases as injection flow ratio increases. 


\section{A. Abdel-Fattah, "Control of Separation Flow in Sudden Enlargement"}

- As the injection flow angle increases, the pressure recovery increases and its maximum value at the reattachment point shifts in upstream direction by increasing the injection flow angle.

- The value of Nusselt number increases as injection Reynolds number increases, also it increases as the injection flow angle increases.

- For all cases of injection in recirculation zone of sudden enlargement, the heat transfer is less than the heat transfer of the flow without injection.

- The comparison between the numerical results and the experimental measurements for average Nusslet number gives good agreement using the k- $\varepsilon$ model with correction of Leschziner and Rodi [16].

\section{Nomenclature}

$\mathrm{A}_{\mathrm{f}}$ cross sectional -area of the flow

As surface area of the heat transfer

b hydraulic parameter of injection jet $\mathrm{mm}$

$\mathrm{c}_{1}, \mathrm{c}_{2}, \mathrm{c}_{\mu}$, empirical constants of $\mathrm{k}-\varepsilon$ model

Cp Pressure coefficient $\left(\frac{\bar{p}-\bar{p}_{i n}}{0.5 \rho U_{m}^{2}}\right)$

d hydraulic parameter of the flow at inlet (mm)

$d_{m}$ Inlet diameter of sudden enlargement ( $\mathrm{mm}$ )

$d_{n}$ Inlet nominal diameter of sudden enlargement (mm)

$D_{n}$ outlet nominal diameter of sudden enlargement (mm)

$\mathrm{h}_{\mathrm{av}} \quad$ Average heat transfer coefficient $\mathrm{W} /\left(\mathrm{m}^{2} \cdot \mathrm{K}\right)$

$\mathrm{k}$ Dimensionless of turbulent kinetic energy $\left(\bar{k} / U_{m}^{2}\right)$

$\mathrm{k}_{\mathrm{c}} \quad$ Thermal conductivity $\mathrm{W} /(\mathrm{m} . \mathrm{K})$

$\bar{k} \quad$ Turbulent kinetic energy $\mathrm{J} / \mathrm{kg}$

$\mathrm{P}$ Dimensionless pressure

$\bar{p} \quad$ Static pressure $\mathrm{N} / \mathrm{m}^{2}$

Pr Laminar Prandtl number

$\operatorname{Pr}_{\mathrm{t}}$ Turbulent Prandtl number

$\bar{q} \quad$ Heat flow rate $\mathrm{W}$

Q Injection ratio $\left(\bar{Q}_{J} / \bar{Q}_{m}\right)$

$\operatorname{Re}_{J}$ Injenction Reynolds number $\left(\operatorname{Re}_{J}=\bar{\rho} u_{J} b / \mu\right)$

$\operatorname{Re}_{m}$ Reynolds number $\left(\operatorname{Re}_{m}=\bar{\rho} U_{m} d / \mu\right)$

$R e_{m t}$ Turbulent Reynolds number $\left(\operatorname{Re}_{\mathrm{mt}}=\bar{\rho} U_{m} d / \bar{\mu}_{t}\right)$

$S \quad$ Formation rate tensor

$\mathrm{T}$ Dimensionless temperature

$\bar{T} \quad$ Temperature $\mathrm{k}$ $\mathrm{u}$ Dimensionless of axial component of local mean velocity $\left(\mathrm{u}=\bar{u} / U_{m}\right)$

$\bar{u}$ Axial component of local mean velocity $(\mathrm{m} / \mathrm{s})$

$u_{J}$ Injection mean velocity of jet $(\mathrm{m} / \mathrm{s})$

$U_{m}$ Inlet mean velocity of sudden enlargement $(\mathrm{m} / \mathrm{s})$

$\mathrm{v}$ Dimensionless of radial component of local mean velocity $\left(\mathrm{v}=\overline{\mathrm{v}} / U_{m}\right)$

$\overline{\mathrm{V}}$ Radial component of local mean velocity $(\mathrm{m} / \mathrm{s})$

r,z Cylindrical coordinates

\section{Greek symbols}

$\mathcal{E}$ Dimensionless dissipation rate of $\mathrm{k}$, $\left(\varepsilon=\bar{\varepsilon} d_{m} / U_{m}^{3}\right)$

$\bar{\varepsilon} \quad$ Dissipation rate of $\mathrm{kJ} / \mathrm{kg}$

$\mu$ Dynamic viscosity $\mathrm{kg} / \mathrm{m} . \mathrm{s}$

$\bar{\rho}$ Density $\mathrm{kg} / \mathrm{m}^{3}$

$\sigma_{\varepsilon} \quad$ Model constant

$\sigma_{\kappa}$ Model constant

\section{Subscripts \\ - Dimension \\ av Average \\ in Inlet \\ $\mathrm{j}$ Injection \\ $\mathrm{m}$ Main \\ n nominal \\ t Turbulent}

\section{REFERENCES}

[1] I. Yilmaz, H. F. Öztop, Turbulance forced convection heat transfer over double forward facing step flow, International Journal of Heat and Mass Transfer 33(2006) 508-517

[2] P. R. Kanna, M. K. Das, Heat Transfer study of two -dimensional laminar incompressible wall jet over backward -facing step, Numerical Heat Transfer Part A, 50 (2006) 165- 187

[3] E. Seo, S. Parameswaran, Numerical computations of steady and unsteady, separation buoyant Flows- Part1: computations with the standard k- $\varepsilon$ model, Numerical Heat Transfer Part A, 42 (2002) 791- 809

[4] D. J. Forliti, P.J. Strykowski, Controlling turbulence in a rearward-facing step combustor using countercurrent shear, Journal of Fluid Engineering, 127(2005) 438-448. 
[5] O. Manca, S. Nardini, K. Khanafer, K.Vafai, Effect of heated wall on mixed convection in a channel with an open cavity, Numerical Heat Transfer PartA, 43 (2003) 259-282

[6] P. O. Iwanik. W.K.S. Chiu, Temperature distribution of an optical fiber traversing through a chemical vapor depositionreactor', Numerical Heat Transfer Part A, 43(2003) 221-237

[7] M. Dianat, Z. Yang, D. Jiang, J. J. McGuirk, Large eddy simulation of scalar Mixing in a coaxial confined jet, Flow Turbulence Combust. 77 (2006) 205-227

[8] A. Brunn, W. Nitsche, Active of turbulent separated flows over slated surfaces, International Journal of Heat and Fluid Flow 27(2006) 748-755

[9] V., I., Terekhov, Yu, M., Mshvidobadze, Experimental investigation flow hydraulic resistance of a cylindrical duct with injection a fan slot jet, Experimental Thermal and Fluid Science 29(2005) 159-167

[10]R. Palm, S. Grundmann, M. Weismüller, S. Sarić, S. Jakirlić, C. Tropea, Experimental characterization and modeling of inflow conditions for a gas turbine swirl combustor, International Journal of Heat and Fluid Flow 27(2006) 924-936.

[11] M. R. Ahmed, S.D. Sharma, Effect of velocity ratio on the turbulent mixing of confined, co axial jets, Experimental Thermal and Fluid Science 22 (2000) 19-33.
[12] S. He, Z. Xu, J.D. Jackson, An experimental investigation of buoyancy- opposed wall jet flow, International Journal of Heat and Fluid Flow, 23(2002) 487-496.

[13]A. Abdel-Fattah., Numerical and experimental study of turbulent impinging twin-jet flow, Experimental Thermal and Fluid Science 31(2007) 1061-1072

[14]A. Abdel-Fattah and Abd El-Baky, Numerical investigation of impinging two dimensional jet on an inclined flat plate, International journal of fluid Mechanics Research 36.I5(2009) 391-413.

[15]B. E. Launder and D.B. Spalding, The numerical computation of turbulent flow, Comput. Methods Appl. Mech. Eng, 3(1974) 269-289

[16] M.A. Leschziner and W. Rodi, Calculation of annular and twin parallel jets using various discretization schemes and turbulence- model variations, ASME Fluids Eng. 103(1981)

[17] R. P. Lindstedt, D.S. Luff and J. H. Whitelaw, Velocity and strain-rate characteristics of opposed isothermal flows, Flow, Turbulence and combustion. 74 (2005) 169-194

[18] Y. Yang and C. Shyu, Numerical study of multiple impinging slot jets with an inclined confinement surface, Numerical Heat Transfer, Part A, 33(1998) 23-37.

[19] S.V. Patankar, Numerical Heat Transfer and Fluid Flow. McGraw-Hill, New York 1980. 